\title{
Transmission Of The Subprime Crisis: Evidence From Industrial And Financial Sectors Of BRIC Countries
}

\author{
Jussi Nikkinen, University of Vaasa, Finland \\ Kashif Saleem, Lappeenranta University of Technology, Finland \\ Minna Martikainen, Hanken School of Economics, Finland
}

\begin{abstract}
Although, there is an apparent consensus about the contagion effects of the current US subprime crisis. However, the transmission and repercussions of US subprime crisis, as well as the nature of the transformation suffered by different economic sectors between the US and other markets are such empirical questions that have not been dealt with comprehensively, yet. In this paper, by utilizing the multivariate GARCH analysis of Engle and Kroner (1995) for which a BEKK representation is adopted, we examine the transmission of the US subprime crisis across BRIC financial markets. Moreover, to identify the extent of contagion, we also inspect the diffusion of US subprime crisis to BRIC equity market's financial and industrial sectors. We found interesting evidence of volatility spillovers from US financial sector to all the BRIC market's financial sectors both in the full sample and crisis period. Similarly, except Chinese industrial sector, we observe contagion effects from US to Brazilian, Russian and Indian equity market's industrial sectors. Our results exhibit direct linkage for both returns and volatility between the US equity market and the BRIC markets. Equity markets of Russia and India, however, were found hardly hit during the crisis period among the BRIC countries. Finally, we found no support for the decoupling view while investigating the fastest growing emerging markets, the BRIC countries.
\end{abstract}

Keywords: Subprime Crisis Transmission; Contagion; BRIC Equity Markets; Financial Sector; Industrial Sector

\section{INTRODUCTION}

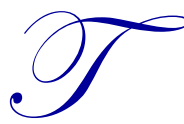

he ongoing subprime crisis originated from the burst of real estate sector bubble in the United States appeared to be the most disastrous one for the financial houses, industrial growth and stock markets around the globe. In fact, this crisis has uncovered the insidious flaws in financial industry regulations and questioned the realism of the global financial system.

Although, there is an apparent consensus about the contagion effects of the current US subprime crisis. However, the transmission and repercussions of US subprime crisis, as well as the nature of the transformation suffered by different economic sectors between the US and other markets are such empirical questions that have not been dealt with comprehensively, yet. Only limited literature is available till today, for instance, by utilizing structural vector autoregressive model Angkinand et al (2009) examines the spillover effects from the U.S. financial crisis to 17 advanced economies. Their results indicate that the extent of interdependence was at peak after the emergence of the U.S. subprime crisis. Similarly, Lee (2012) investigates the correlations between the US returns and 20 international stock returns consisting both developed and emerging markets. Furthermore, Y1lmaz (2010) through variance decomposition analysis of the VAR model inspect the extent of contagion and interdependence across the East Asian equity markets during the current global financial crisis and found evidence of direct linkage between the equity markets with regards to returns and volatility. Furthermore, by applying dynamic correlations Fidrmuc and Korhonen (2010) investigate the transmission of US subprime crisis to China and India and conclude that the current financial crisis has had a significant effect on their economic developments and business cycles. 
More recently, Cheung et al (2010) analyze the market interdependence and spillover effect of credit risk during 2007-2009 global financial crisis to UK, Hong Kong, Japan, Australia, Russia and China and found evidence of contagion. Dimitriou and Simos (2013) found empirical evidence of contagion of the USA subprime financial crisis to EMU, China and Japan equity markets.

Studies investigating the affects of US subprime crisis on BRIC countries are even scarce, exceptions includes, for instance, Bhar and Nikolova (2009) who investigate return and volatility spillovers and dynamic correlation in the BRIC equity markets. Bianconi et al (2013) study the co movement of stock and bond markets BRIC during the U.S. financial crisis. Similarly, Aloui et al (2011) study the co movement of equity markets between BRIC and US market; their empirical findings confirm strong support of time-varying dependence between each of the BRIC markets and the US market.

This paper examines the transmission of the ongoing US subprime crisis to Brazil, Russia, India and China, representatives of the fastest growing emerging economies of the world, and investigates if, and to what extent, these emerging markets have been affected by the crisis, by analyzing their stock markets and industrial and financial sectors of their equity markets. These particular markets are of special interest since BRIC economies have been perhaps the key performers in the world economy in the past two decades. During their gradual process of development developed world has certainly recognized their economic importance and even BRIC markets have begun to influence economic developments in other emerging countries by setting standards to grow. This growth has been dominated particularly by the rising Chinese economy, due to its export driven policies and a huge foreign investment from developed countries. Within no time, China has turn out to be an important player for the global economy. At the same time, India, Russia and Brazil are in chase of Chinese economic development. In short, growth in BRIC economies has changed the direction of economic performance across the globe. Between 1988 and 2008, the share of BRIC economies GDP in the world economy increased from $7 \%$ to $15 \%$ (valued at market exchange rates). Among the countries Chinese GDP in the world economy increased from $1.7 \%$ to $7.1 \%$, Brazil and Russia contribute $2.7 \%$ each, while Brazil's share of global output was only $2 \%$. Enormous increased in the stock market indices of BRIC countries during the last decade, for example, Brazil's Bovespa Index rose $342 \%$, China's Shanghai Composite Index rose 75\%, India's Sensex Index rose 250\% and Russia's Micex Index rose 638\%, is another evidence of their potential role in the future of global economy.

Another objective of this paper is to examine the so called "decoupling" theory phenomenon, See, for instance, Ricardo et al (2010) and Eichengreen and Park (2008). At the early phase of US subprime crisis, many believed that BRIC economies were isolated from the global economic chaos. The argument behind this believe was the so called decoupling theory, which assumes that the U.S. economy is no longer the driver of world economic growth but the fastest growing economies, such as emerging Asia and Europe. However many recent studies, such as, Frank and Hesse (2009), Dooley and Hutchison (2009) as well as Pula and Peltonen (2009) found no support for the decoupling view while investigation of emerging markets of Asia. Since BRIC markets are known as the economic engine of the world today it would be interesting to see whether decoupling theory is true for BRIC countries.

On the whole, to investigating the interdependence among US equity market and BRIC equity markets as well as to explore the contagious affects of US subprime crisis on BRIC equity markets, Among others, Following Saleem (2008), Shamiri and Isa (2009) and Caporale et al (2006) we purpose Engle and Kroner (1995) multivariate GARCH analysis for which a BEKK representation is adopted. Additionally, in view of the fact that BRIC markets have strong links with the global economy through trade and financial channels; we examine the transmission of US subprime crisis to BRIC equity market's financial and industrial sectors to identify the extent of contagion. Four pair-wise models for global indices are estimated for USA with Brazil, Russia, India and China and eight bi-variate models are estimated for sectoral indices, representing the financial and the industrial sectors in each market analysed on the basis of daily total return indices. We divide our analysis in three parts, pre crisis (Jan. 2000 - Jul 2007), crisis period 1 (Aug 2007 - Aug. 2008), start of the world wide credit crunch in August 2007 but before the Lehman Brothers' bankruptcy in September 2008, crisis period 2 (Sep. 2008 - Dec. 2009) Lehman Brothers' bankruptcy in September 2008 till the end of 2009. Our results exhibit direct linkage for both return s and volatility between the US equity market and the BRIC markets. For instance, in case of return spillovers, both crisis periods exhibit highly significant return spillovers from US market to all the BRIC countries markets and their sectors. 
Results for the pre crisis period shows that India and Russian equity returns as well as their financial and industrial sector returns were highly effected by the movements in US equity market and its financial and industrial sectors. Likewise, results for volatility establish clear evidence of contagion, at least in equity and industrial sector, however, only Russian financial sector found severely hit after the Lehman Brothers' bankruptcy. In addition, following prior research, to examine the long-term relationship among the markets we utilize Johansen cointegration test and to examine the causality affects between two markets we apply Granger Causality Test. Both the conventional methods also support our results obtained by using multivariate GARCH- BEKK representation.

It is our contention that a clearer understanding of the US subprime crisis from the perspective of international interdependence during crisis periods hold value for persons such as international investors, multinational corporations and portfolio managers seeking to minimize or manage their exposures to financial risk. International transmission of stock market volatility also impacts corporate capital budgeting decisions, investor consumption decisions and other business cycle variables.

The plan of the paper is as follows. The next section describes the bivariate GARCH models used to study the volatility spillovers among stock markets and sectoral indices and to identify the extent of US subprime contagion. Section 3 presents the data in this study. Section 4 shows the empirical results. Section 5 concludes.

\section{MODEL SPECIFICATION}

We start our empirical specification with a bivariate VAR-GARCH $(1,1)$ model that accommodates each market's returns and the returns of other markets lagged one period. ${ }^{1}$

$$
\begin{aligned}
& {\left[\begin{array}{l}
r_{1, t} \\
r_{2, t}
\end{array}\right]=\left[\begin{array}{l}
a_{1,0} \\
a_{2,0}
\end{array}\right]+\left[\begin{array}{ll}
\beta_{1,1} & \beta_{1,2} \\
\beta_{2,1} & \beta_{2,2}
\end{array}\right]\left[\begin{array}{l}
r_{1, t-1} \\
r_{2, t-1}
\end{array}\right]+\left[\begin{array}{l}
\mu_{1, t} \\
\mu_{2, t}
\end{array}\right]} \\
& u_{t} \Omega_{t-1} \sim N\left(0, H_{t}\right),
\end{aligned}
$$

where $r_{t}$ is a $n \times 1$ vector of daily returns at time $t$ for each market. The $n \times 1$ vector of random errors $\mu_{t}$ represents the innovation for each market at time $t$ with its corresponding $n \times n$ conditional variance-covariance matrix $H_{t}$. The market information available at time $\mathrm{t}-1$ is represented by the information set $\Omega_{\mathrm{t}-1}$. The $\mathrm{n} \times 1$ vector, $\alpha$, represents the constant. The own market mean spillovers and cross-market mean spillovers are measured by the estimates of matrix $\beta$ elements, the parameters of the vector autoregressive term. This multivariate structure thus facilitates the measurement of the effects of innovations in the mean stock returns of one series on its own lagged returns and those of the lagged returns of other markets.

Given the above expression, and following Engle and Kroner (1995), the conditional covariance matrix can be stated as:

$$
H_{t}=C_{0}^{\prime} C_{0}+A_{11}^{\prime} \varepsilon_{t-1} \varepsilon_{t-1}^{\prime} A_{11}+G_{11}^{\prime} H_{t-1} G_{11}
$$

where the parameter matrices for the variance equation are defined as $\mathrm{C}_{0}$, which is restricted to be lower triangular and two unrestricted matrices $A_{11}$ and $\mathrm{G}_{11}(\mathrm{Gema})$. Thus, the second moment can be represented by:

$$
H_{t}=C_{0}^{\prime} C_{0}+\left[\begin{array}{ll}
a_{11} & a_{12} \\
a_{21} & a_{22}
\end{array}\right]^{\prime}\left[\begin{array}{cc}
\varepsilon_{1, t-1}^{2} & \varepsilon_{1, t-1}, \varepsilon_{2, t-1} \\
\varepsilon_{1, t-1}, \varepsilon_{2, t-1} & \varepsilon_{2, t-1}^{2}
\end{array}\right]\left[\begin{array}{ll}
a_{11} & a_{12} \\
a_{21} & a_{22}
\end{array}\right]+\left[\begin{array}{ll}
g_{11} & g_{12} \\
g_{21} & g_{22}
\end{array}\right]^{\prime} H_{t-1}\left[\begin{array}{ll}
g_{11} & g_{12} \\
g_{21} & g_{22}
\end{array}\right]
$$

\footnotetext{
${ }^{1}$ This model is based on the bivariate GARCH $(1,1)$-BEKK representation proposed by Engle and Kroner (1995).
} 
Following Engle and Kroner (1995) the above system can be estimated by the maximum likelihood estimation which can be optimised by using the Berndt, Hall, Hall and Hausman (BHHH) algorithm. From equations (4) we obtain the conditional $\log$ likelihood function $\mathrm{L}(\theta)$ for a sample of $\mathrm{T}$ observations:

$$
\begin{aligned}
& L(\theta)=\sum_{t=1}^{T} l_{t}(\theta) \\
& l_{t}(\theta)=-\log 2 \pi-1 / 2 \log \left|H_{t}(\theta)\right|-1 / 2 \varepsilon_{t}^{\prime}(\theta) H_{t}^{-1}(\theta) \varepsilon_{t}(\theta)
\end{aligned}
$$

where $\theta$ denotes the vector of all the unknown parameters. Numerical maximisation of equation (4) yields the maximum likelihood estimates with asymptotic standard errors.

Finally, to test the null hypothesis that the model is correctly specified, or equivalently, that the noise terms, $\mu_{\mathrm{t}}$, are random, the Ljung-Box Q-statistic is used. It is assumed to be asymptotically distributed as $\chi 2$ with ( $\mathrm{p}-\mathrm{k}$ ) degrees of freedom, where $\mathrm{k}$ is the number of explanatory variables. Moreover, as robustness checks we also examine the long-term relationship among the markets by utilizing Johansen cointegration test. Finally to examine the causality affects between two markets we apply Granger Causality Test.

\section{DATA AND DISCRIPTIVE STATISTICS}

The data comprise daily total return indices calculated by DataStream for the US equity market, its Industrial and Financial sector, and Brazilian, Russian, Indian and Chinese equity markets and their Industrial and Financial sectors. The dataset starts from January 2000 and ends at December 2009, yielding 2609 observations in total for each series. While analysing the contagion effect of US subprime crisis 2007, two crisis periods were defined, first from August 2007 (burst of the mortgage bubble, assumed to have occurred) to August 2008, before the Lehman collapse and second from September 2008 to December 2009. Figure 1 shows the development of equity markets of BRIC countries and US market and Figure 2 and 3 presents the development of financial and industrial sectors of BRIC countries and US market. All the data are retrieved from DataStream, and daily returns are constructed as the first difference of logarithmic prices multiplied by 100 . Stationarity in the time series is checked by applying the Augmented Dickey Fuller (ADF) test. To check the null hypothesis of normal distribution we calculate Jarque-Bera test statistic. Finally, to investigate the null that autocorrelation coefficients up to 26 lags are zero, we compute Ljung and Box (1978) test statistic, together with the ARCH LM-statistic (five lags) on each returns series. The results (not presented, available on request) allow us to reject the null hypothesis that returns have unit root in favor of alternate hypothesis of stationarity (even at 1\% MacKinnon critical value), reject the normality and allow us to use GARCH specification through LB statistics and ARCH LM-statistic.

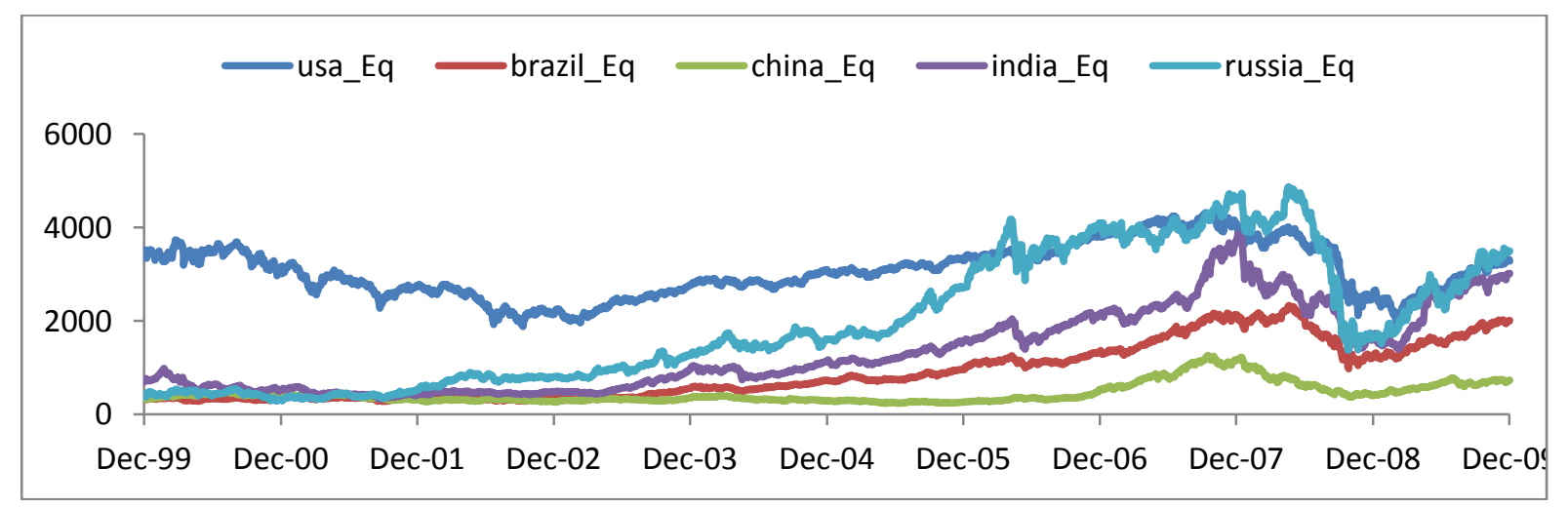

Figure 1: Equity Market Development 


\section{EMPIRICAL RESULTS}

Our empirical results answer the theoretical questions formulated in the previous sections. First, to examine the return and volatility transmission of US stock market four pair-wise models are estimated utilizing bivariate GARCH frame work, for which a BEKK representation is adopted (see, e.g., Engle and Kroner, 1995). Moreover, in view of the fact that BRIC markets have strong links with the global economy through trade and financial channels; we examine the transmission of US subprime crisis to BRIC equity market's financial and industrial sectors to identify the extent of contagion, eight bivariate models are estimated for sectoral indices, representing the financial and the industrial sectors in each market analysed on the basis of daily total return indices calculated by DataStream from January 2000 to December 2009.

Table 1 Volatility Spillovers between US and Brazilian Equity Markets and Their Industrial and Financial Sectors Estimated from a Bivariate VAR - GARCH(1, 1)-BEKK Model of Daily Return Indices

The diagonal and off diagonal elements in matrix Beta measures own and cross-market return effect and diagonal and off diagonal elements in matrix Gama measures own and cross-market GARCH effects. EQ represents equity markets, IND and FIN stands for industrial and financial sector of the equity markets respectively. i and j represent USA and Brazil. Sample period is from January 2000 to August 2007 consisting of 1071 daily observations for pre crisis period. Crisis period is chosen between August 2007 and August 2008 and September 2008 till December 2009, representing before and after the collapse of Lehman Brothers.

\begin{tabular}{|c|c|c|c|c|c|}
\hline \multicolumn{6}{|c|}{ Panel A: VAR - GARCH(1, 1)-BEKK Estimations - Pre Crisis } \\
\hline & Coeff & Signif & & Coeff & Signif \\
\hline$\overline{\text { Beta_EQi,j }}$ & 0.040 & 0.018 & Gema_EQi,j & 0.016 & 0.127 \\
\hline Beta_EQj,i & 0.004 & 0.895 & Gema_EQj,i & 0.003 & 0.626 \\
\hline Beta_INDi,j & -0.018 & 0.209 & Gema_INDi,j & -0.006 & 0.514 \\
\hline Beta_INDj,i & 0.057 & 0.014 & Gema_INDj,i & -0.019 & 0.152 \\
\hline Beta_FINi,j & 0.008 & 0.562 & Gema_FINi,j & 0.017 & 0.110 \\
\hline Beta FINj,i & 0.013 & 0.611 & Gema_FINj,i & 0.001 & 0.855 \\
\hline \multicolumn{6}{|c|}{ Panel B: VAR - GARCH(1, 1)-BEKK Estimations - Crisis Period 1(August 2007 - August 2008) } \\
\hline & Coeff & Signif & & Coeff & Signif \\
\hline Beta_EQi,j & -0.058 & 0.215 & Gema_EQi,j & -0.210 & 0.594 \\
\hline Beta_EQj,i & 0.115 & 0.264 & Gema_EQj,i & -0.070 & 0.760 \\
\hline Beta_INDi,j & 0.032 & 0.588 & Gema_INDi,j & 0.679 & 0.331 \\
\hline Beta_INDj,i & 0.072 & 0.368 & Gema_INDj,i & -0.608 & 0.054 \\
\hline Beta_FINi,j & -0.132 & 0.069 & Gema_FINi,j & 0.125 & 0.010 \\
\hline Beta FINj,i & 0.178 & 0.000 & Gema_FINj,i & -0.272 & 0.035 \\
\hline \multicolumn{6}{|c|}{ Panel C: VAR - GARCH(1, 1)-BEKK Estimations - Crisis Period 2(September 2008 - December 2009) } \\
\hline & Coeff & Signif & & Coeff & Signif \\
\hline Beta_EQi,j & -0.059 & 0.368 & Gema_EQi,j & 0.139 & 0.001 \\
\hline Beta_EQj,i & 0.156 & 0.021 & Gema_EQj,i & -0.017 & 0.000 \\
\hline Beta_INDi,j & 0.011 & 0.860 & Gema_INDi,j & 0.101 & 0.003 \\
\hline Beta_INDj,i & 0.066 & 0.148 & Gema_INDj,i & -0.034 & 0.289 \\
\hline Beta_FINi,j & 0.060 & 0.443 & Gema_FINi,j & 0.039 & 0.049 \\
\hline Beta_FINj,i & 0.009 & 0.812 & Gema_FINj,i & -0.008 & 0.762 \\
\hline
\end{tabular}

We first look at matrix $\beta$ in the mean equation, Eq. (1), captured by the parameters $\beta_{i j}$, in order to see the relationship in terms of returns across the countries and sectors in each pair. Next we examine the estimated results of the time-varying variance-covariance Eq. (4) in the system. The matrices G (Gemma) reported in Table 1-4 help examine the relationship in terms of volatility as stated in Eq. (4). The off-diagonal elements of matrices $G$ capture the cross-market effects such as shock and volatility spillovers among the pairs. 


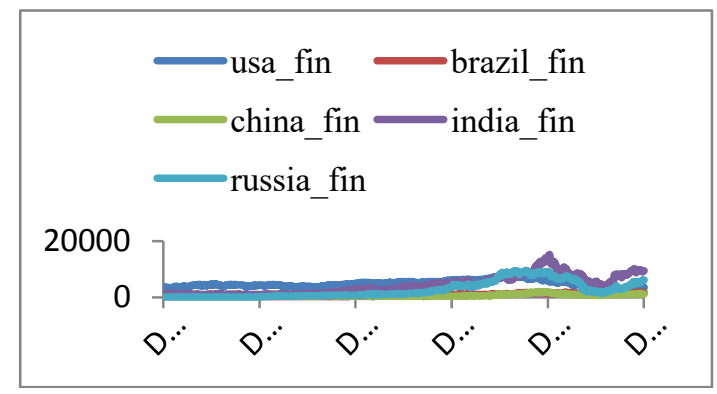

Figure 2: Financial Sector Development

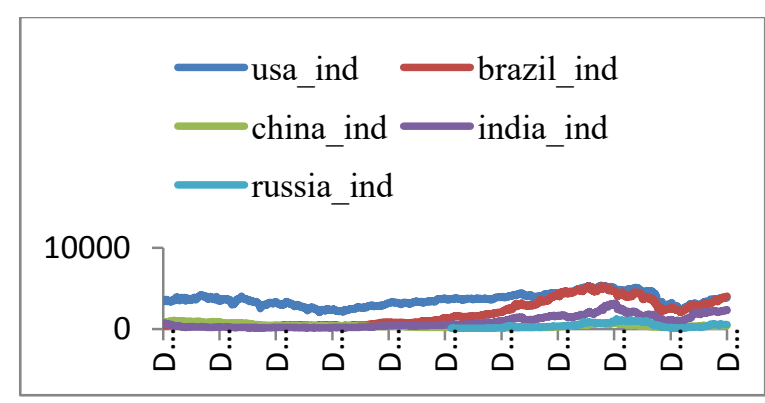

Figure 3: Industrial Sector Development

Table 2 Volatility Spillovers between US and Russian Equity Markets and Their Industrial and Financial Sectors Estimated from a Bivariate VAR - GARCH(1, 1)-BEKK Model of Daily Return Indices

The diagonal and off diagonal elements in matrix Beta measures own and cross-market return effect and diagonal and off diagonal elements in matrix Gama measures own and cross-market GARCH effects. EQ represents equity markets, IND and FIN stands for industrial and financial sector of the equity markets respectively. i and j represent USA and Russia. Sample period is from January 2000 to August 2007 consisting of 1071 daily observations for pre crisis period. Crisis period is chosen between August 2007 and August 2008 and September 2008 till December 2009, representing before and after the collapse of Lehman Brothers.

\begin{tabular}{|c|c|c|c|c|c|}
\hline \multicolumn{6}{|c|}{ Panel A: VAR - GARCH(1, 1)-BEKK Estimations - Pre Crisis } \\
\hline & Coeff & Signif & & Coeff & Signif \\
\hline Beta_EQi,j & -0.011 & 0.257 & Gema_EQi,j & 0.052 & 0.005 \\
\hline Beta_EQj,i & 0.293 & 0.000 & Gema_EQj,i & 0.004 & 0.442 \\
\hline Beta_INDi,j & 0.008 & 0.284 & Gema_INDi,j & 1.767 & 0.000 \\
\hline Beta_INDj,i & 0.299 & 0.015 & Gema_INDj,i & 0.025 & 0.033 \\
\hline Beta_FINi,j & -0.008 & 0.271 & Gema_FINi,j & 0.058 & 0.001 \\
\hline Beta FINj,i & 0.283 & 0.000 & Gema_FINj,i & 0.006 & 0.168 \\
\hline \multicolumn{6}{|c|}{ Panel A: VAR - GARCH(1, 1)-BEKK Estimations - Crisis Period 1(August 2007 - August 2008) } \\
\hline & Coeff & Signif & & Coeff & Signif \\
\hline Beta_EQi,j & -0.044 & 0.379 & Gema_EQi,j & -0.560 & 0.000 \\
\hline Beta_EQj,i & 0.284 & 0.000 & Gema_EQj,i & 0.108 & 0.144 \\
\hline Beta_INDi,j & -0.076 & 0.016 & Gema_INDi,j & 0.265 & 0.000 \\
\hline Beta_INDj,i & 0.225 & 0.014 & Gema_INDj,i & -0.071 & 0.000 \\
\hline Beta_FINi,j & -0.188 & 0.004 & Gema_FINi,j & -0.182 & 0.000 \\
\hline Beta_FINj,i & 0.310 & 0.000 & Gema_FINj,i & 0.199 & 0.002 \\
\hline \multicolumn{6}{|c|}{ Panel A: VAR - GARCH(1, 1)-BEKK Estimations - Crisis Period 2(September 2008 - December 2009) } \\
\hline & Coeff & Signif & & Coeff & Signif \\
\hline$\overline{\text { Beta_EQi,j }}$ & 0.027 & 0.395 & Gema_EQi,j & -0.121 & 0.021 \\
\hline Beta_EQj,i & 0.299 & 0.003 & Gema_EQj,i & 0.036 & 0.020 \\
\hline Beta_INDi,j & -0.027 & 0.233 & Gema_INDi,j & 0.427 & 0.000 \\
\hline Beta_INDj,i & 0.274 & 0.012 & Gema_INDj,i & -0.072 & 0.000 \\
\hline Beta_FINi,j & 0.067 & 0.053 & Gema_FINi,j & -0.023 & 0.412 \\
\hline Beta_FINj,i & 0.024 & 0.702 & Gema_FINj,i & -0.006 & 0.731 \\
\hline
\end{tabular}

Results are available from table 1-4. We divide our analysis in three parts, pre crisis (Jan. 2000 - Jul 2007), crisis period 1 (Aug 2007 - Aug. 2008), start of the world wide credit crunch in August 2007 but before the Lehman Brothers' bankruptcy in September 2008, crisis period 2 (Sep. 2008 - Dec. 2009) Lehman Brothers' bankruptcy in September 2008 till the end of 2009. 
Table 3 Volatility Spillovers between US and Indian Equity Markets and Their Industrial and Financial Sectors Estimated from a Bivariate VAR - GARCH(1, 1)-BEKK Model of Daily Return Indices

The diagonal and off diagonal elements in matrix Beta measures own and cross-market return effect and diagonal and off diagonal elements in matrix Gama measures own and cross-market GARCH effects. EQ represents equity markets, IND and FIN stands for industrial and financial sector of the equity markets respectively. $\mathrm{i}$ and $\mathrm{j}$ represent USA and India. Sample period is from January 2000 to August 2007 consisting of 1071 daily observations for pre crisis period. Crisis period is chosen between August 2007 and August 2008 and September 2008 till December 2009, representing before and after the collapse of Lehman Brothers.

\begin{tabular}{|c|c|c|c|c|c|}
\hline \multicolumn{6}{|c|}{ Panel A: VAR - GARCH(1, 1)-BEKK Estimations - Pre Crisis } \\
\hline & Coeff & Signif & & Coeff & Signif \\
\hline Beta_EQi,j & 0.006 & 0.594 & Gema_EQi,j & 0.008 & 0.286 \\
\hline Beta_EQj,i & 0.184 & 0.000 & Gema_EQj,i & -0.012 & 0.008 \\
\hline Beta_INDi,j & 0.011 & 0.392 & Gema_INDi,j & 0.000 & 0.936 \\
\hline Beta_INDj,i & 0.136 & 0.000 & Gema_INDj,i & -0.005 & 0.524 \\
\hline Beta_FINi,j & 0.000 & 0.967 & Gema_FINi,j & 0.004 & 0.515 \\
\hline Beta FINj,i & 0.135 & 0.000 & Gema_FINj,i & -0.005 & 0.144 \\
\hline \multicolumn{6}{|c|}{ Panel A: VAR - GARCH(1, 1)-BEKK Estimations - Crisis Period 1(August 2007 - August 2008) } \\
\hline & Coeff & Signif & & Coeff & Signif \\
\hline$\overline{\text { Beta_EQi,j }}$ & -0.085 & 0.011 & Gema_EQi,j & -0.090 & 0.670 \\
\hline Beta_EQj,i & 0.450 & 0.000 & Gema_EQj,i & -0.177 & 0.006 \\
\hline Beta INDi,j & -0.061 & 0.053 & Gema INDi,j & 0.266 & 0.048 \\
\hline Beta_INDj,i & 0.316 & 0.000 & Gema_INDj,i & -0.110 & 0.008 \\
\hline Beta_FINi,j & -0.133 & 0.001 & Gema_FINi,j & -0.133 & 0.001 \\
\hline Beta_FINj,i & 0.477 & 0.000 & Gema_FINj,i & 0.477 & 0.000 \\
\hline \multicolumn{6}{|c|}{ Panel A: VAR - GARCH(1, 1)-BEKK Estimations - Crisis Period 2(September 2008 - December 2009) } \\
\hline & Coeff & Signif & & Coeff & Signif \\
\hline Beta_EQi,j & 0.130 & 0.002 & Gema_EQi,j & 0.154 & 0.000 \\
\hline Beta_EQj,i & 0.145 & 0.007 & Gema_EQj,i & -0.099 & 0.000 \\
\hline Beta_INDi,j & 0.088 & 0.088 & Gema_INDi,j & 0.133 & 0.000 \\
\hline Beta_INDj,i & 0.132 & 0.023 & Gema_INDj,i & -0.094 & 0.002 \\
\hline Beta_FINi,j & 0.109 & 0.036 & Gema_FINi,j & 0.109 & 0.036 \\
\hline Beta FINj,i & 0.113 & 0.003 & Gema_FINj,i & 0.113 & 0.003 \\
\hline
\end{tabular}

Our results exhibit direct linkage for both returns and volatility between the US equity market and the BRIC markets. For instance, in case of return spillovers, both crisis periods exhibit highly significant return spillovers from US market to all the BRIC countries markets and their sectors. Results for the pre crisis period shows that India and Russian equity returns as well as their financial and industrial sector returns were highly effected by the movements in US equity market and its financial and industrial sectors. Likewise, results for volatility establish clear evidence of contagion, at least in equity and industrial sector, however, only Russian financial sector found severely hit after the Lehman Brothers' bankruptcy. In addition, following prior research, to examine the long-term relationship among the markets we utilize Johansen cointegration test, (results available on request), and to examine the causality affects between two markets we apply Granger Causality test (results available on request) Both the conventional methods also support our results obtained by using multivariate GARCH- BEKK representation Moreover, one can argue that the so called "decoupling" theory does not hold true at least for the BRIC countries. 
Table 4 Volatility Spillovers between US and Chinese Equity Markets and Their Industrial and Financial Sectors Estimated from a Bivariate VAR - GARCH(1, 1)-BEKK Model of Daily Return Indices

The diagonal and off diagonal elements in matrix Beta measures own and cross-market return effect and diagonal and off diagonal elements in matrix Gama measures own and cross-market GARCH effects. EQ represents equity markets, IND and FIN stands for industrial and financial sector of the equity markets respectively. $i$ and $j$ represent USA and China. Sample period is from January 2000 to August 2007 consisting of 1071 daily observations for pre crisis period. Crisis period is chosen between August 2007 and August 2008 and September 2008 till December 2009, representing before and after the collapse of Lehman Brothers.

\begin{tabular}{|c|c|c|c|c|c|}
\hline \multicolumn{6}{|c|}{ Panel A: VAR - GARCH(1, 1)-BEKK Estimations - Pre Crisis } \\
\hline & Coeff & Signif & & Coeff & Signif \\
\hline Beta_EQi,j & 0.006 & 0.657 & Gema_EQi,j & 0.006 & 0.143 \\
\hline Beta_EQj,i & 0.027 & 0.287 & Gema_EQj,i & 0.010 & 0.003 \\
\hline Beta_INDi,j & 0.003 & 0.850 & Gema_INDi,j & 0.000 & 0.943 \\
\hline Beta_INDj,i & 0.017 & 0.453 & Gema_INDj,i & 0.008 & 0.003 \\
\hline Beta_FINi,j & 0.007 & 0.522 & Gema_FINi,j & 0.002 & 0.706 \\
\hline Beta_FINj,i & 0.043 & 0.136 & Gema_FINj,i & 0.010 & 0.090 \\
\hline \multicolumn{6}{|c|}{ Panel A: VAR - GARCH(1, 1)-BEKK Estimations - Crisis Period 1(August 2007 - August 2008) } \\
\hline & Coeff & Signif & & Coeff & Signif \\
\hline Beta_EQi,j & -0.008 & 0.801 & Gema_EQi,j & -1.324 & 0.000 \\
\hline Beta_EQj,i & 0.470 & 0.000 & Gema_EQj,i & -0.283 & 0.000 \\
\hline Beta_INDi,j & -0.043 & 0.182 & Gema_INDi,j & 0.304 & 0.092 \\
\hline Beta_INDj,i & 0.257 & 0.036 & Gema_INDj,i & -0.039 & 0.473 \\
\hline Beta_FINi,j & 0.006 & 0.891 & Gema_FINi,j & 0.096 & 0.026 \\
\hline Beta_FINj,i & 0.346 & 0.000 & Gema_FINj,i & -0.072 & 0.063 \\
\hline \multicolumn{6}{|c|}{ Panel A: VAR - GARCH(1, 1)-BEKK Estimations - Crisis Period 2(September 2008 - December 2009) } \\
\hline & Coeff & Signif & & Coeff & Signif \\
\hline Beta_EQi,j & 0.077 & 0.030 & Gema_EQi,j & -0.036 & 0.032 \\
\hline Beta_EQj,i & 0.222 & 0.000 & Gema_EQj,i & 0.020 & 0.282 \\
\hline Beta_INDi,j & 0.076 & 0.075 & Gema_INDi,j & -0.038 & 0.064 \\
\hline Beta_INDj,i & 0.175 & 0.000 & Gema_INDj,i & 0.021 & 0.339 \\
\hline Beta_FINi,j & 0.034 & 0.490 & Gema_FINi,j & -0.007 & 0.499 \\
\hline Beta_FINj,i & 0.094 & 0.001 & Gema_FINj,i & -0.002 & 0.909 \\
\hline
\end{tabular}

\section{DIAGNOSTIC TESTS}

We also estimate the Ljung-Box Q-statistic used to test the null hypothesis that the model is correctly specified, or equivalently, that the noise terms are random. We calculate both standardized and standardized squared residuals up to lag 24 for each modelled pair. Results show (not reported, available on request) no series dependence in the squared standardized residuals, indicating the appropriateness of the GARCH-BEKK model.

\section{SUMMARY AND CONCLUSIONS}

In this paper we have examined the linkage between US equity market and the fastest growing economies of the world, the BRIC countries (Brazil, Russian, India and China) equity markets, and the transmission of the US subprime crisis of 2007-2009 to BRIC countries. We use a bivariate GARCH-BEKK model proposed by Engle and Kroner (1995). By utilizing daily total return indices, four pair-wise models are estimated, namely, USA-Brazil, USA-Russia, USA-India, and USA-China. Additionally, in view of the fact that BRIC markets have strong links with the global economy through trade and financial channels; we examine the transmission of US subprime crisis to BRIC equity market's financial and industrial sectors to identify the extent of contagion. Eight bivariate models are estimated for sectoral indices, representing the financial and the industrial sectors in each market analysed. While analyzing the contagion effect of US Subprime crisis 2007-2009, we consider two crisis periods, crisis period 1 (Aug 2007 - Aug. 2008), start of the world wide credit crunch in August 2007 but before the Lehman Brothers' bankruptcy in September 2008, crisis period 2 (Sep. 2008 - Dec. 2009) Lehman Brothers' bankruptcy in September 2008 till the end of 2009. 
We found evidence of direct linkage between the US equity market and BRIC markets, both in regards of returns and volatility, For instance, in case of return spillovers, both crisis periods exhibit highly significant return spillovers from US market to all the BRIC countries markets and their sectors. Results for the pre crisis period shows that India and Russian equity returns as well as their financial and industrial sector returns were highly effected by the movements in US equity market and its financial and industrial sectors. Likewise, results for volatility establish clear evidence of contagion, at least in equity and industrial sector, however, only Russian financial sector found severely hit after the Lehman Brothers' bankruptcy. In addition, following prior research, to examine the long-term relationship among the markets and sectors we utilize Johansen cointegration test and finally to examine the causality affects between the markets and sectors we apply Granger Causality Test. Both the conventional methods to identify interdependence also support our results obtained by using multivariate GARCHBEKK representation. Moreover, we found no support for the decoupling view while investigating the fastest growing emerging markets, the BRIC countries.

Thus, within the context of the US subprime crisis, our results offers a better understanding of the nature of international interdependence during the crisis period which is very valuable for the international investors, multinational corporations and portfolio managers, who all are involved in minimizing and managing their financial risk exposure. Likewise, international transmission of stock market volatility can impact on corporate capital budgeting decisions, investors' consumption decisions, and other business cycle variables.

\section{ACKNOWLEDGEMENTS}

The authors would like to thank participants of 17th Annual Conference of the Multinational Finance Society. Barcelona, 2010 and XIII International Academic Conference on Economic and Social Development. Moscow, 2012 for their valuable comments and discussions. This research (Project No. 132913 and 134125) is partially supported by Academy of Finland. All remaining errors are our own.

\section{AUTHOR INFORMATION}

Jussi Nikkinen, Ph.D., is a professor of Financial Accounting at University of Vaasa, Department of Accounting and Finance, Vaasa, Finland. E-mail: in@uwasa.fi

Kashif Saleem, Ph.D., is an Associate Professor (Finance) at Lappeenranta School of Business, Lappeenranta University of Technology, Finland. He received his MSc. degree, specialized in computational finance from Hanken School of Economics, Finland and his Ph.D. in Business Administration (Finance) from Lappeenranta University of Technology, Finland. In addition to these schools, Dr. Kashif has also taught different finance courses at the Graduate school of management, Saint Petersburg State University, Russia. Postal Address: PO Box 20, FIN-53851 Lappeenranta, Finland. E-mail: Kashif.saleem@lut.fi (Corresponding author)

Minna Martikainen, Ph.D., is a professor of Financial Accounting in Hanken School of Economics (Finland). Previously she has worked as professor in Aalto University School of Business and in Lappeenranta University of Technology (LUT). In LUT she also worked as the vice rector for international affairs for two years. Moreover, previously she has worked in University of Vaasa as researcher and as visiting researcher in Louisiana State University, USA. Dr Martikainen's research interests in the area of financial accounting are profitability and grow. E-mail: minna.martikainen@aalto.fi

\section{REFERENCES}

1. Angkinand, A.P., Barth, J.R. and H. Kim. 2010. Spillover effects from the U.S. financial crisis: Some time series evidence from national stock returns in The Financial and Economic Crises: An International Perspective, ed. Benton E. Gup, 24-52. Cheltenham: Edward Elgar Publishing.

2. Aloui, R., Aissa, M.S.B., and D.K. Nguyen. 2011. Global financial crisis, extreme interdependences, and contagion effects: the role of economic structure? Journal of Banking and Finance 35, 130-141.

3. Bhar, R., and B. Nikolova. 2009. Return, volatility spillovers and dynamic correlation in the BRIC equity markets: an analysis using a bivariate EGARCH framework. Global Finance Journal 19: 203-218. 
4. Bianconi, M., Yoshino, J.A., and M.A. Machado de Sousa. 2013. BRIC and the U.S. financial crisis: An empirical investigation of stock and bond markets. Emerging Markets Review 14: 76-109

5. Caporale, G.M., Pittis, N., and N. Spagnolo. 2006. Volatility transmission and financial crisis. Journal of Economics and Finance 30: 376-390.

6. Cheung, W., Fung, S., and S.C. Tsai. 2010. Global capital market interdependence and spillover effect of credit risk: evidence from the 2007-2009 global financial crisis. Applied Financial Economics, 20: 85-103.

7. Dimitriou, D., and T. Simos. (2013) Contagion channels of the USA subprime financial crisis: Evidence from USA, EMU, China, and Japan equity markets. Journal of Financial Economic Policy 5: 61 - 71.

8. Dooley, M. and M. Hutchison. 2009. Transmission of the U.S. subprime crisis to emerging markets:

Evidence on the decoupling-recoupling hypothesis. Journal of International Money and Finance 28: 13311349.

9. Eichengreen, B., and Y.C. Park. 2008. Asia and the decoupling myth. Working Paper. University of California, Berkeley.

10. Engle, R.F. and K.F. Kroner. 1995. Multivariate Simultaneous Generalized ARCH. Econometric Theory 11: $122-150$.

11. Fidrmuc, J. and I. Korhonen. 2010. The impact of the global financial crisis on business cycles in Asian emerging economies. Journal of Asian Economics 21: 293-303.

12. Frank, N. and H. Hesse. 2009. Financial Spillovers to Emerging Markets During the Global Financial Crisis. Czech Journal of Economics and Finance 59: 507-521.

13. Lee, H.Y. 2012. Contagion in international stock markets during the subprime mortgage crisis. International Journal of Economics and Financial Issues 2: 41-53.

14. Shamiri, A., and Z. Isa. 2009. The US crisis and the volatility spillover across Southeast Asian Stock Markets. International Research Journal of Finance and Economics 34: 7-17.

15. Saleem, K. 2009. International linkage of the Russian market and the Russian financial crisis: a multivariate GARCH analysis. Research in International Business and Finance 23:243-256.

16. Pula, G. and T. A. Peltonen. 2009. Has Emerging Asia Decoupled? An Analysis of Production and Trade Linkages Using the Asian International Input-Output Table. European Central Bank Working Paper Series No 993.

17. Ricardo, L., Ferhan, S., and C. Mali. 2010. The impact of the great recession on emerging markets. IMF Working Paper, 10/237.

18. Yilmaz, K. 2010. Return and volatility spillovers among the East Asian equity markets. Journal of Asian Economics 21:304-313. 